ORIGINAL ARTICLE

\title{
Who can drive home from the emergency department? A questionnaire based study of emergency physicians' knowledge of DVLA guidelines
}

\section{A Frampton}

Emerg Med J 2003;20:526-530

Correspondence to: Dr A Frampton, Accident and Emergency Department, Salisbury District Hospital, Odstock Road, Salisbury, Wiltshire, UK; anneframpton 2003@ yahoo.co.uk

Accepted for publication 10 December 2002

\begin{abstract}
Objective: To determine whether doctors working in emergency departments are aware which of the common conditions seen have driving restrictions associated with them and whether they routinely advise patients of these restrictions.

Methods: 200 questionnaires were distributed to all grades of doctor currently working in 15 emergency departments in Wessex and the south west. The survey was anonymous so follow up of non-responders was not possible. Doctors were asked to indicate which of the 20 commonly seen conditions listed had DVLA guidelines restricting driving activity at least temporarily, and in which of these conditions they actually advised patients appropriately about their driving. In addition the MDU, GMC, and the Department of Transport web site were contacted to establish what they considered to be good medical practice regarding issuing advice about driving.

Results: 102 doctors (51\%) responded to the survey. Knowledge regarding restrictions for various conditions varied, with $87.5 \%$ responding correctly about a first fit to only $7.8 \%$ regarding a collapse query cause. With regard to advising patients, $79.4 \%$ of doctors responding said that they routinely advised patients about stopping driving after a first fit, $32 \%$ advised patients after a single transient ischaemic attack, and only $7 \%$ after a collapse query cause.

Conclusions: Doctors working in emergency departments are aware of conditions that lead to an inpatient admission that have driving restrictions. However, knowledge of conditions where patients are likely to be discharged was not as complete and advice was less likely to be given to patients. Emergency department doctors need to be more aware of restrictions that apply to conditions where patients are to be discharged.
\end{abstract}

D riving is an inherently dangerous activity associated with significant mortality and morbidity, leading to 3500 deaths and 40000 serious injuries from road traffic accidents in the UK each year. ${ }^{12}$ The road traffic act 1988, section 92-94, ${ }^{3}$ deals with a person's fitness to hold/and or continue to hold entitlement to drive various categories of vehicles. Medical standards, set by the Department of Transport's medical advisory panels, are used by the medical advisers to the DVLA to decide whether a person is fit or unfit to hold a licence. ${ }^{4}$ These standards are published by the DVLA and guidelines issued to inform both patients and the medical profession of those conditions that necessitate a restriction in driving however temporary.

Previous studies, King et al, ${ }^{5}$ MacMahon et al, ${ }^{6}$ and Kelly et $a l^{7}$ have found knowledge among doctors to be poor. Few doctors questioned knew restrictions for common medical conditions and only $14 \%$ of syncope patients in one study could recall the doctor attending them inquiring about driving. ${ }^{6}$

Huge numbers of ill and injured patients attend the emergency department daily, a large proportion of these will be discharged with or without further follow up. It is essential the emergency department doctors are aware of conditions that may have driving restrictions. Especially relevant are conditions such as transient ischaemic attacks, collapses, and first fits where patients are likely to be discharged with outpatient follow up and investigation arranged if they have made a full recovery. These conditions often occur in comparatively young and previously fit people in who the need to restrict driving will not have crossed their minds.
The aim of this questionnaire was not to determine whether doctors knew the details of restrictions of each individual condition, guidelines are readily available in most departments and on the DVLA web site, but rather to discover if doctors currently working in emergency departments are aware when they should be referring to these guidelines and if they were informing patients routinely of these restrictions.

\section{METHODS}

Two hundred questionnaires were sent to emergency physicians currently working in 15 emergency departments in Wessex and the south west. The questionnaire was comprised of two questions. The first asked doctors to indicate which of 20 listed conditions that are commonly seen in the emergency department had restrictions according to current DVLA guidelines. The second question asked doctors to indicate in which of the same 20 conditions, if any, they routinely informed patients of the appropriate restrictions. The survey was anonymous so it was not possible to contact non-responders, however a reply paid envelope was included with every questionnaire to encourage as many people to respond as possible. Doctors were requested to fill in the questionnaire without reference to the currently published guidelines.

\section{RESULTS}

In total 102 doctors (51\%) replied to the questionnaire; 16 consultants, 16 specialist registrars, 20 staff grades, 41 SHOs, and 9 clinical fellows. The length of experience in emergency medicine ranged from less than six months to greater than 10 years. When analysing the replies, the conditions were split into four groups-neurological conditions, collapse query 


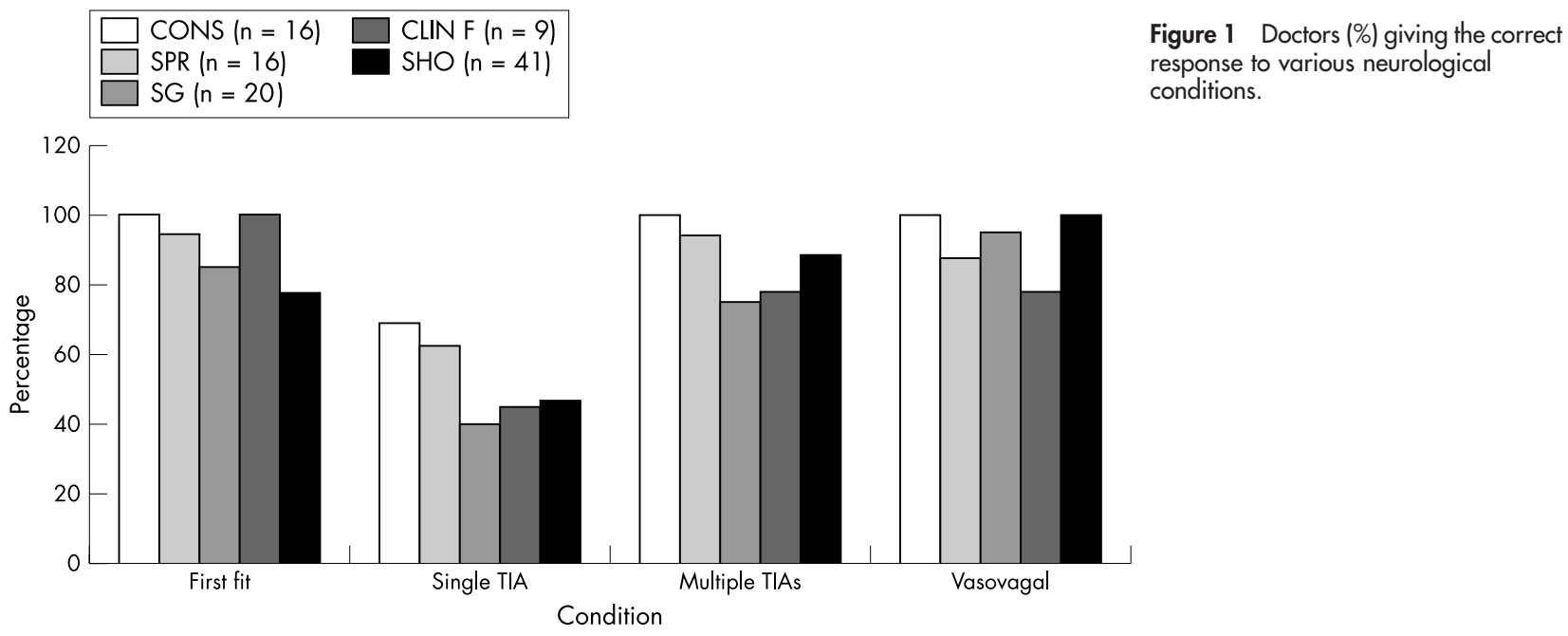

cause, cardiovascular conditions, and psychiatric/drug and alcohol related conditions. The results were as follows;

(1) Neurological conditions (figl). Overall $87.5 \%$ of doctors were aware that restrictions applied to patients presenting with a first fit. However, when asked about a single TIA, a condition also likely to result in discharge and outpatient follow up if completely resolved, the overall percentage was only $51.9 \%$, with the awareness amongst SHOs, clinical fellows and staff grades nearer $40 \%$. Some $87.2 \%$ of doctors were aware that multiple TIAs were associated with restrictions and almost all were aware that straightforward vasovagal attacks carry no restriction to driving.

(2) Collapse query cause (fig 2). Knowledge of driving restrictions in this group of patients was poorer. When presenting with a loss of consciousness or altered awareness, likely to be unexplained syncope and with a low risk of recurrence (normal cardiovascular and neurological examination and normal ECG), patients should abstain from driving for four weeks and inform the DVLA. Only $7.8 \%$ of doctors in this survey were aware that there were any restrictions, with knowledge particularly poor among SHOs, staff grades and clinical fellows who are likely to see most of these patients. Patients who present with loss of consciousness or altered awareness, probably unexplained syncope but with a high risk of recurrence (abnormal ECG, clinical evidence of structural heart disease, syncope while lying or sitting or $>1$ episode in six months) are required to inform the DVLA. If a cause is identified and treated driving can begin after four weeks, however if no cause is found then driving is not permitted for six months. In this survey $44.6 \%$ of doctors were aware that restrictions applied to these two groups.

(3) Cardiovascular disease (fig 3). Of the conditions listed in this category, only unstable angina and myocardial infarction had any restrictions, both of these conditions will lead to admission and inpatient assessment. Overall $56.8 \%$ of doctors responded correctly to unstable angina, and $78.4 \%$ to myocardial infarction.

(4) Psychiatric conditions/alcohol dependency/drug misuse (fig 4). Overall $38.2 \%$ of the doctors who responded to the survey were aware that there were driving restrictions that applied to patients with severe depression. Some $55.9 \%$ gave the correct answer for acute psychosis, $53.9 \%$ gave the correct answer to alcohol dependency, $28.4 \%$ for persistent use of cannabis, $43.4 \%$ for heroin use, and $42 \%$ for benzodiazepine dependency.

The number of doctors who routinely explain relevant restrictions to patients was also studied (fig 5). Some doctors commented that for various conditions patients were likely to be admitted and it was therefore the responsibility of the admitting team to advise on driving. Similarly, some of the more chronic conditions such as alcohol and drug dependence may be more appropriately addressed by the patients' GP. However, it was considered important that emergency

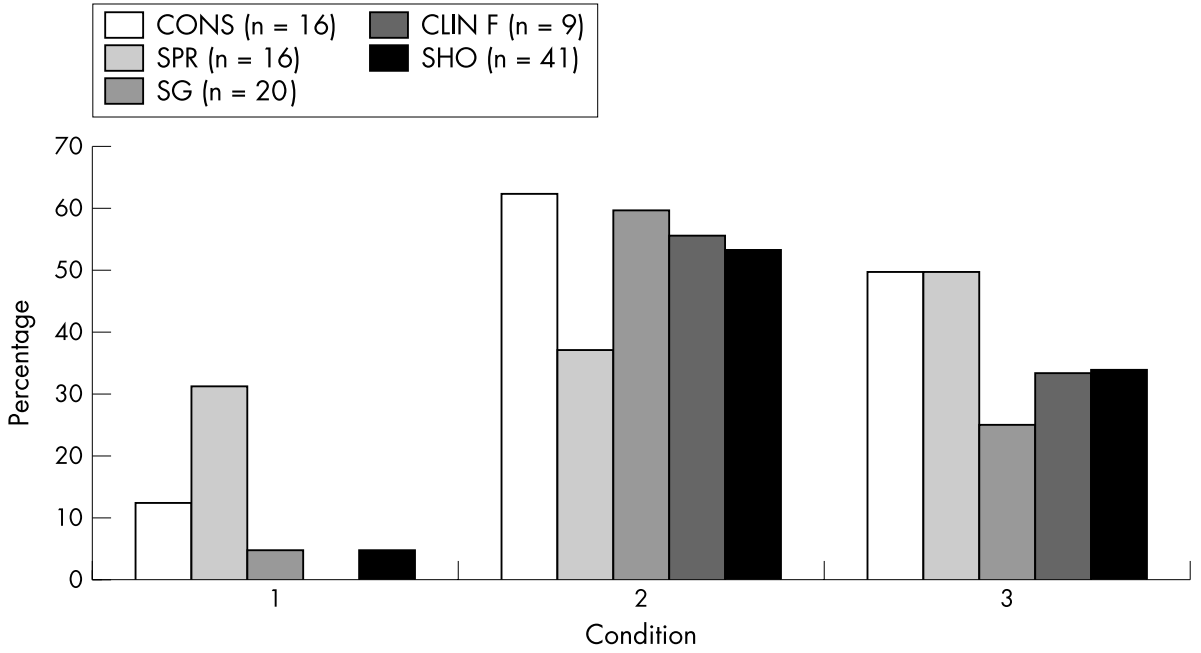

Figure 2 Doctors (\%) giving the correct response to collapse query cause. 1 , collapse? cause (low risk of recurrence); 2 , collapse?cause (high risk of recurrence); 3 , collapse cause identified and treated. 


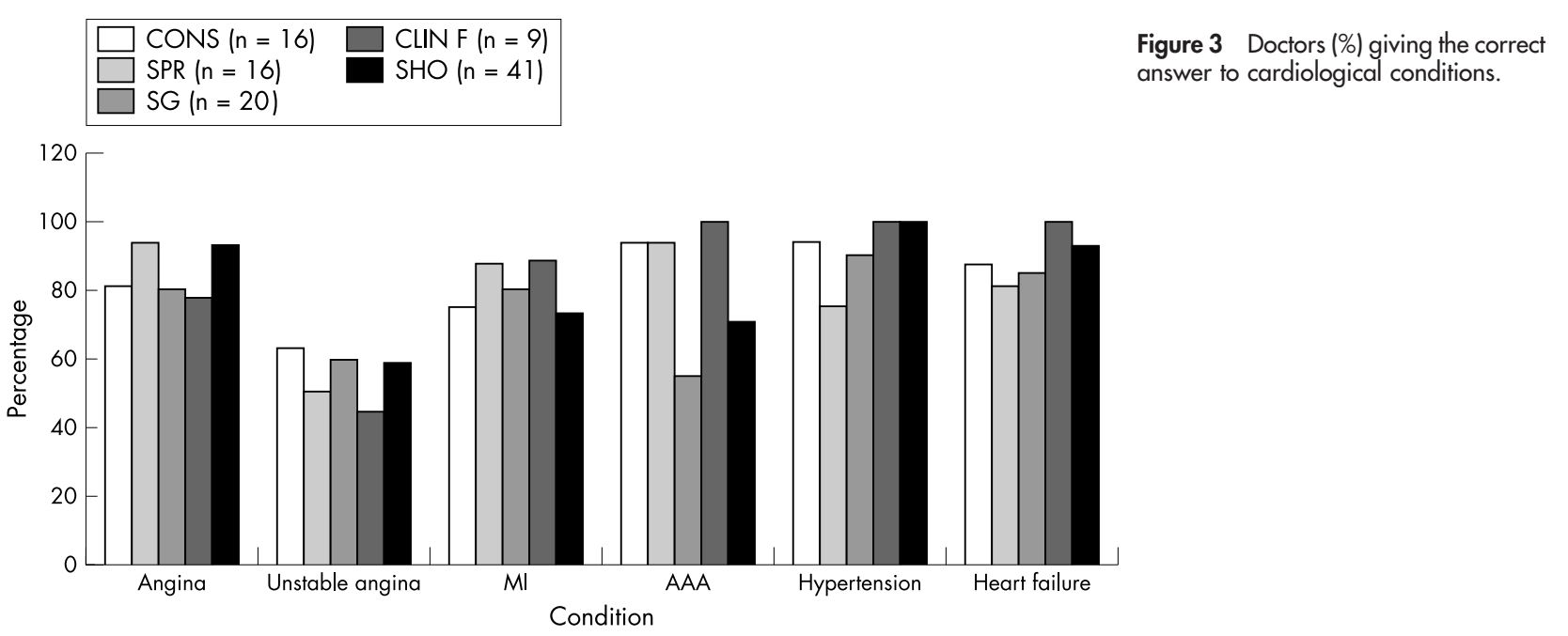

physicians should advise patients who present with conditions that have restrictions but who may be discharged from the department, for example; first fit, single TIA, and collapse query cause. (See table 1 for a summary of the guidelines for these conditions). Overall $79.4 \%$ of respondents informed patients of driving restrictions following a first fit. Only $32 \%$ reported advising patients after a single TIA, 7\% advised patients after a collapse with low risk of recurrence, $31 \%$ after a collapse with high risk of recurrence, and $14.7 \%$ after a collapse where the cause had been identified and treated.

\section{DISCUSSION}

The $51 \%$ response rate to this study was better than that achieved in previous similar undertakings, previous response rates have been around $30 \% .^{5}$ Those who failed to respond could not be followed up because of the anonymous nature of the survey. There are numerous reasons why doctors may not respond, however as knowledge of the correct responses probably increases the incentive to respond, it is probable that those who failed to respond had less knowledge than those who did reply.

Conditions with no restriction to driving were intentionally included in the questionnaire to prevent doctors simply ticking each condition, however it is possible that this survey over-estimated knowledge. Firstly, it was not possible to determine whether anyone had consulted the DVLA web site or guidelines before attempting the survey, although, by making the survey anonymous, it was hoped that this would be avoided. Secondly, doctors may have guessed that conditions had restrictions associated, particularly as no details of restrictions were required.

Medical conditions probably play a part in causing major road accidents in less than $1 \%$ of cases. ${ }^{5}$ However, the literature on chronic illness and their contribution to road traffic accidents is conflicting. Waller ${ }^{8}$ concludes that drivers with diabetes, epilepsy, cardiovascular disease, mental disorders, and alcoholism averaged twice as many accidents per 1000000 miles of driving as a control group. His group of patients contained a large proportion of people with epilepsy. Ysander $^{9}$ by contrast, in a study of drivers with chronic disease (mainly diabetes, cerebrovascular disease and renal disease) found that the percentage of accidents in the disease group was half that of the control group. The National Highway Traffic safety administration in Utah undertook a study looking at the same question. ${ }^{10}$ They found that when viewed as a group, drivers who were licensed with medical conditions had higher risks for crashes, violations and at fault crashes than the comparison group. Grattan and Jeffcoate found that 1.5 minor or serious injury accidents per 1000 were attributable to sudden illness of the driver or rider. ${ }^{1}$

Irvine suggested that when assessing a person's fitness to drive there are three key questions that should be asked, ${ }^{4}$ these are:

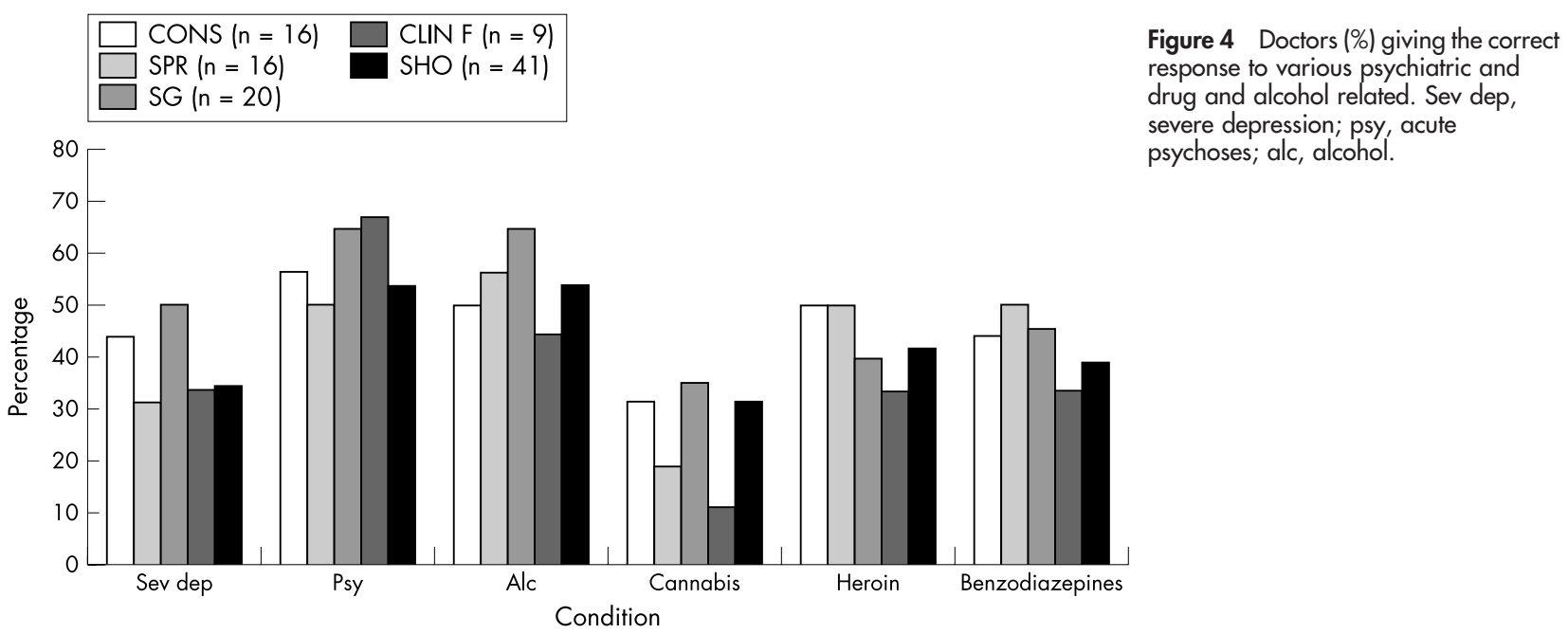

Figure 4 Doctors (\%) giving the correct to various psychiatric and severe depression; psy, acute psychoses; alc, alcohol. 


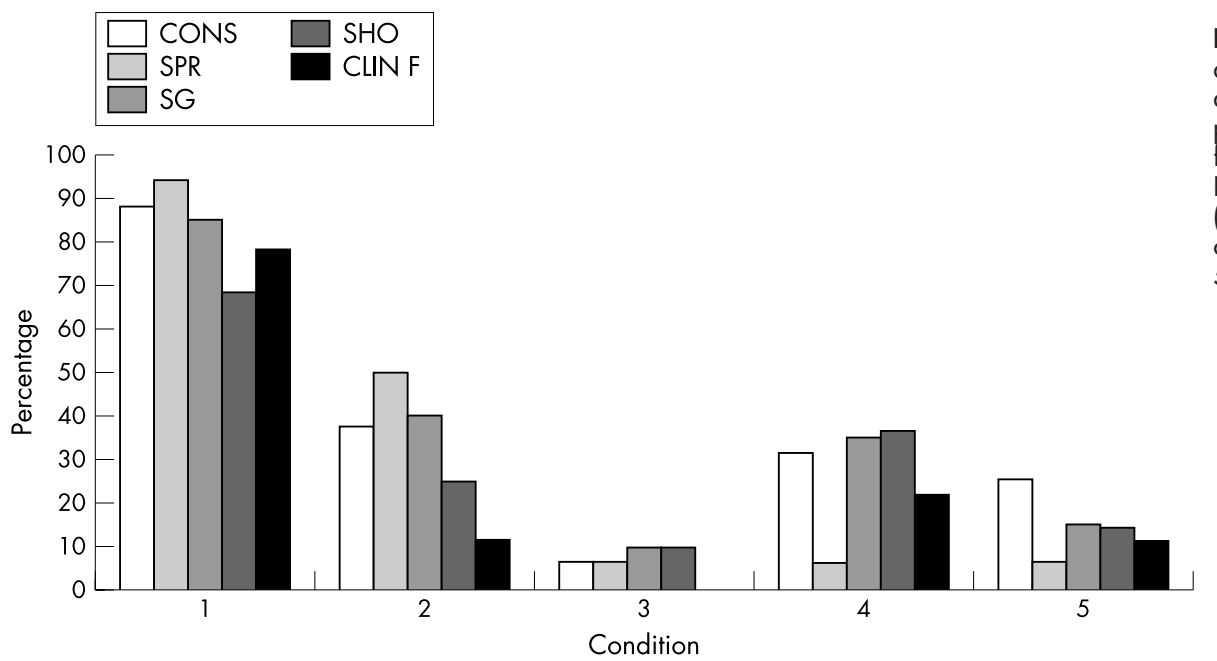

Figure 5 Doctors (\%) routinely advising patients regarding restriction associated with conditions where patients are likely to be discharged from the emergency department. 1, First fit; 2 , single TIA; 3 , collapse?cause (low risk of recurrence); 4 , collapse?cause (high risk of recurrence; 5 , collapse, cause found and treated.

- Is there significant evidence of a cortical impairment (for example, dementia, post-CVA, alcohol or drug misuse) such that a person is likely to be a source of danger at the wheel?

- Is the person liable to sudden or disabling episodes of collapse, altered awareness, loss of consciousness or visual disturbance from whatever medical cause ( such as sudden hypoglycaemia, epilepsy, cardiac arrhythmia, or Menieres disease)?

- Does the person have an inadequate standard of vision?

If the answer is yes to any of these questions, the correct advice, which should be recorded in the notes, is for patients to:

- Stop driving

- Notify the DVLA

\section{- Notify their motor insurer}

Section $94(1)$ of the road traffic act $1988^{3}$ places a duty upon the holder of a driving licence to inform the relevant authority if at any time during the currency of the licence he suffers from a relevant or progressive disability. Under section 92(1), the definition of "relevant disability" includes any disability that is likely to cause the holder of the licence to be a source of danger to the public when driving a vehicle. Although the prime responsibility for informing the authorities lies with the patients, physicians have a duty of care to society that overrides right to confidentiality when the patient cannot or will not conform. Ultimate responsibility lies with the physician who knows the diagnosis. ${ }^{1}$

Doctors, who omit to advise patients appropriately, may be open to legal action. Thus if a medical practitioner fails to advise a motorist that they are unfit to drive because of a

\begin{tabular}{|c|c|c|}
\hline Condition & Group 1 entitlement & Group 2 entitlement \\
\hline First epileptic seizure/solitary fit & $\begin{array}{l}\text { One year off driving with } \\
\text { medical review before restarting } \\
\text { driving }\end{array}$ & $\begin{array}{l}\text { After a first unprovoked seizure, } \\
\text { drivers must demonstrate } 10 \text { years } \\
\text { freedom from further seizures, without } \\
\text { anticonvulsant medication in that time }\end{array}$ \\
\hline $\begin{array}{l}\text { Cerebrovascular disease: } \\
\text { Including stroke due to occlusive } \\
\text { vascular disease, spontaneous } \\
\text { intracerebral haemorrhage, TIA, and } \\
\text { amaurosis fugax }\end{array}$ & $\begin{array}{l}\text { Must not drive for at least one } \\
\text { month. } \\
\text { May resume driving after this } \\
\text { time if recovery is satisfactory. }\end{array}$ & $\begin{array}{l}\text { Recommended refusal/revocation for } \\
\text { at least } 12 \text { months after a stroke or } \\
\text { TIA. }\end{array}$ \\
\hline $\begin{array}{l}\text { Loss of consciousness/loss or altered } \\
\text { awareness likely to be unexplained } \\
\text { syncope and low risk of recurrence } \\
\text { These have no relevant abnormality on } \\
\text { CVS and neurological examination and } \\
\text { normal ECG }\end{array}$ & $\begin{array}{l}\text { Can drive four weeks after the } \\
\text { event }\end{array}$ & Can drive three months after the event \\
\hline 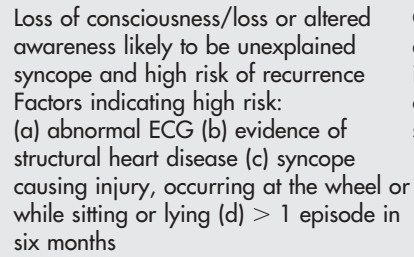 & $\begin{array}{l}\text { Can drive four weeks after the } \\
\text { event if the cause has been } \\
\text { identified and treated If no } \\
\text { cause identified then require } \\
\text { six months off }\end{array}$ & $\begin{array}{l}\text { Can drive three months after the event } \\
\text { if the cause has been identified and } \\
\text { treated. If no cause identified, then } \\
\text { licence refused/revoked for one year }\end{array}$ \\
\hline
\end{tabular}


Causes of 2000 road accidents involving collapse at the wheel, based on reports to the police by the DVLA ${ }^{12}$

- Epilepsy (38\%)

- Blackouts $(21 \%)$

- Diabetic people taking insulin (19\%)

- Heart condition $(8 \%)$

- CVA $(7 \%)$

- Others (7\%)

condition known to the medical practitioner, it is likely that the medical practitioner would be guilty of negligence in their duty of care. They would therefore be liable for any harm arising as a consequence of their negligence and could be sued on that basis. In a case sited by the DVLA a GP failed to advise his patient who had recently suffered from a TIA to stop driving and inform the DVLA and his insurance company. The patient had a serious accident involving several vehicles, and the insurance company failed to compensate on the grounds that his insurance was null and void because of his previous TIA. The GP was therefore responsible as he had failed to give his patient necessary advice and was subsequently prosecuted. ${ }^{5}$ In such circumstances it is up to the court to decide on liability and the amount of any compensation that might be due. One potential mistake is to assume that the patient drives only a car, and to base the advice on that. This study has not concentrated on drivers of HGVs or public transport, however, more stringent rules apply in these cases and should not be overlooked.

Anecdotally the cases in which the MDU have become involved usually involve GPs as they are traditionally in the best position to advise patients (direct communication from the MDU). However, in the case of conditions with short driving restrictions of only weeks or a few months it is possible that patients seen in the emergency department may not have any contact with their GP within the period of the restriction. The MDU were aware of a number of cases where insurers had failed to pay out because they felt the patient should have been advised not to drive by the doctor attending to them.

On the whole emergency physicians were aware of the restrictions for most serious illnesses that required hospital admission. While it is essential to be aware that these conditions will result in a restriction in driving activity, this advice is probably best left to the admitting teams rather than bombarding patients with information on admission. Of note however was the lack of awareness of restrictions associated with conditions where patients were likely to be discharged from the emergency department. These patients by definition are likely to have fully recovered from the initial event by the time of discharge and are more likely to continue to drive. It is this group that emergency physicians need to be aware of and advise them accordingly.

\section{REFERENCES}

1 Binns H, Camm J. Driving and arrhythmias. BMJ 2002;324:927-8.

2 Department of the Environment, Transport and the Regions. Tomorrow's roads: safer for everyone. The government's road safety strategy and casualty target for 2010.1.1 Road accidents. http://www.roads.detr.gov.uk/ roadsafety/strategy/tomorrow/2.htm (accessed 1 Jun 2001).

3 Road Traffic Act. London: HMSO, 1988.

4 Irvine R. The driver, the doctor and the law. Postgrad Med J 1994;238:668-74.

5 King D, Benbow S, Barrett J. The law and medical fitness to drive-a study of doctors' knowledge. Postgrad Med J 1992;68:624-8.

6 MacMahon M, O'Neill D, Kenny R. Syncope: driving advice is frequently overlooked. Postgrad Med J 1996;72:561-3.

7 Kelly R, Warke T, Steele I. Medical restrictions to driving: the awareness of patients and doctors. Postgrad Med J 1999;75:537-9.

8 Waller J. Chronic medical conditions and traffic safety. A review of the Californian experience. N Engl J Med 1965;273:1413-20.

9 Ysander L. The safety of drivers with chronic diseases. Br J Ind Med 1966;23:28-36.

10 Harris S, Jolly B, Runge J, et al. Medical conditions and driver crash risk: do licence restrictions affect public safety? Ann Emerg Med 2000;36:164-6.

11 Gratten E, Jeffcoate G. Medical factors and road accidents. BMJ 1968;1:75-9.

12 Petch M. Taks Force Report. Driving and heart disease. Eur Heart J 1998;19:1165-77.

13 DVLA. DVLA guidelines at a glance. http://www.dvlagov.uk/at_a_glance (accessed 1 Dec 2002) 